Discussion

Papers

Balancing and Intraday Market

Design:

Options for Wind Integration 
Opinions expressed in this paper are those of the author(s) and do not necessarily reflect views of the institute.

IMPRESSUM

(C) DIW Berlin, 2011

DIW Berlin

German Institute for Economic Research

Mohrenstr. 58

10117 Berlin

Tel. $+49(30) 89789-0$

Fax +49 (30) $89789-200$

http://www.diw.de

ISSN print edition $1433-0210$

ISSN electronic edition 1619-4535

Papers can be downloaded free of charge from the DIW Berlin website:

http://www.diw.de/discussionpapers

Discussion Papers of DIW Berlin are indexed in RePEc and SSRN:

http://ideas.repec.org/s/diw/diwwpp.html

http://www.ssrn.com/link/DIW-Berlin-German-Inst-Econ-Res.html 


\title{
Balancing and Intraday Market Design: Options for Wind Integration
}

\author{
Frieder Borggrefe ${ }^{+} \&$ Karsten Neuhoff*
}

October $2011^{\circ}$

\begin{abstract}
EU Member States increase deployment of intermittent renewable energy sources to deliver the $20 \%$ renewable target formulated in the European Renewables Directive of 2008 . To incorporate these intermittent sources, a power market needs to be flexible enough to accommodate short-term forecasts and quick turn transactions. This flexibility is particularly valuable with respect to wind energy, where wind forecast uncertainty decreases significantly in the final 24 hours before actual generation. Therefore, current designs of intraday and balancing markets need to be altered to make full use of the flexibility of the transmission system and the different generation technologies to effectively respond to increased uncertainty. This paper explores the current power market designs in European countries and North America and assesses these designs against criteria that evaluate whether they are able to adequately handle wind intermittency.
\end{abstract}

Keywords: Power market design, integrating renewables, wind energy, balancing, intraday

\footnotetext{
$+\quad$ University of Cologne, Germany

* Climate Policy Initiative (CPI) / DIW Berlin - e-mail (karsten.neuhoff@cpiberlin.org).

- We thank Julian Barquin, Christian Nabe, and Benjamin F. Hobbs for all their valuable comments and input. This paper has been produced in support of the "EU Intelligent Energy Europe program" RE-shaping project which also funded part of the research along with Climate Policy Initiative.
} 

The growing share of wind and other intermittent generation sources in the European power supply increases the uncertainty about power production in day-ahead and longer-term predictions ${ }^{1}$. More accurate forecasts closer to production time reduce this uncertainty. This paper provides six criteria that power market designs need to satisfy in order to allow market participants and system operators to make full use of this information and thus limit the uncertainty and facilitate integration of intermittent renewable energy sources at lower costs and larger volumes, while also increasing system security.

Historically, balancing markets have been the only markets to provide reserve and response operations. System operators contract this reserve and response capacity in day-ahead and longer-term markets with generators to provide flexibility that can be called upon on short notice to balance the system when forced power plant outages or load prediction errors occur. Balancing was only necessary for events of small probabilities (power station failures) or for small volumes (as in the case of load prediction errors); the amount of reserve capacity contracted was thus large compared to the small share of actual electricity requested.

Balancing services were provided nationally, or in the case of Germany, within the region of the TSO. Mutual support between regions was restricted to emergency situations, such as unexpected power plant failures, and not remunerated (only energy that was provided had to be returned). Most power markets imposed penalties for deviations from day-ahead schedules to limit demand for balancing power.

In recent years renewable energy and newly installed wind power have prompted additional demand for reserve and response operations. This demand arose predominantly due to the uncertainty of day-ahead forecasts for renewable feed-ins. This trend will continue as EU Member States increase the deployment of wind power and other intermittent renewable energy sources to deliver the $20 \%$ renewable target formulated in the European Renewables Directive of 2008. Therefore, intraday and balancing markets need to be adjusted to allow the TSOs to appropriately respond to increased uncertainty.

The forecast error for wind decreases distinctly with a shorter lead-time (DENA, 2005; DENA, 2010; Focken et al, 2002; Von Roon and Wagner, 2009). Different studies (Muesgens and

\footnotetext{
${ }^{1}$ In this paper we focus on market design issues for reserve and response markets both within a country and between European Member States. Glachant and Finon (2010) further point out, that wind energy integration into electricity markets creates economic challenges on various additional fronts: support scheme design, strategic behaviour in the presence of large-scale wind energy, and new methods for assessing the economic value of wind power.
} 
Neuhoff, 2002; Tradewind 2009) point out that system costs for balancing wind uncertainty can be significantly reduced if an improved market design allows for optimisation of dispatch across the entire system based on wind forecasts with lead-times reduced to 1-4 hours ahead of physical dispatch. In markets unable to adapt to changing wind forecasts during the day, large volumes a significant amount of balancing reserve capacity and of real-time balancing is required. EWIS (2010) and Tradewind (2009) quantify the resulting additional costs for electricity generation due to the increased start-up and part-load costs to provide balancing power.

The EU has made some progress towards integrating power markets, but today's intraday and balancing market designs are far from a fully efficient and harmonised market. In the third Energy Package, a path for further regulatory harmonisation was laid, which aims to foster a common energy market. The paper provides criteria that the market design must satisfy in order to support the large scale integration of renewables.

- Facilitate system-wide intraday adjustments to respond to improving wind forecasts, to ensure that the least cost generation capacity provides power and ancillary services.

- Allow for the joint provision and adjustment of energy and balancing services; to reduce the amount of capacity needed to provide balancing services and to operate on part load.

- Manage the joint provision of power across multiple hours; a broader set of actors can contribute energy and balancing services in day-ahead and intraday markets if they can coordinate sales across adjacent hours (thus more accurately reflecting technical constraints of power stations like ramp-up rates or start-up costs).

- Capture benefits from international integration of the power system; the transmission network is the most flexible component of the power system, but requires fully integrated intraday and balancing markets to replace more costly generation assets and enhance system security.

- Integrate the demand side into intraday and balancing markets; creating incentives and systems that allow the demand side to fully contribute to the available flexibility.

- Effectively monitor market power; to ensure that cost-reflective intraday pricing bids encourage efficient dispatch choices and 1.) Limits costs for integrating intermittent renewables, 2.) Reduces the risk for market participants exposed to intraday adjustments, and 3.) Limits the need for utilities to balance within their portfolio and thus increases participation.

This paper is structured as follows. The uncertainty of wind forecasts and opportunities to reduce it are discussed in Section 2. Section 3 discusses the flexibility of the power system to 
deal with the uncertainty. In Section 4, the above six criteria for making use of the flexibility of the power system and opportunities to reduce wind uncertainties are introduced; a critical assessment of which is explored in relation to the effectiveness of current European power market designs. Section 5 describes recent EU developments and discusses possible next steps; with concluding remarks in Section 6.

\section{$2 \quad$ Uncertainty of wind forecasts, and opportunities to reduce it}

The power system has to deal with three main sources of uncertainty: demand uncertainty and load prediction errors ${ }^{2}$, failure of power plants, and the uncertainty of wind. Figure 1 illustrates that the aggregate uncertainty about the balance of power supply and demand increases with uncertainties of the individual components.

The following factors need to be considered when evaluating the impact of wind uncertainty on the power system:

- Uncertainty about wind projections decline during the last 24 hours. The demand and supply uncertainty that has to be balanced in real time can be reduced significantly if additional information and updated wind forecasts within the last hours before physical dispatch are used effectively.

- The aggregate uncertainty is less than the sum of the individual uncertainties as long as errors in wind projections, demand projections, and power failure stations are not fully correlated (Dany and Haubrich, 2002). The factor that can contribute the biggest real-time imbalance of supply and demand is likely the failure of large power stations or transmission lines. If uncertainty in predictions of wind output is smaller than uncertainties about other factors, it might only have a small impact on realtime balancing needs.

There are three ways to reduce uncertainty.

\footnotetext{
${ }^{2}$ Demand variations can be further distinguished as: 1.) Load forecast errors, i.e. the deviation of actual demand from the forecasted load of electricity, 2.) Stochastic noise of the electricity demand arising from the deviation of the load level of each second from the quarter-hourly load average, and 3.) Leaps of electricity supply due to early or late delivery of electricity through a scheduled power plant.
} 
Figure 1: Forecasting errors from demand uncertainty, wind uncertainty and power plant failure ${ }^{3}$.
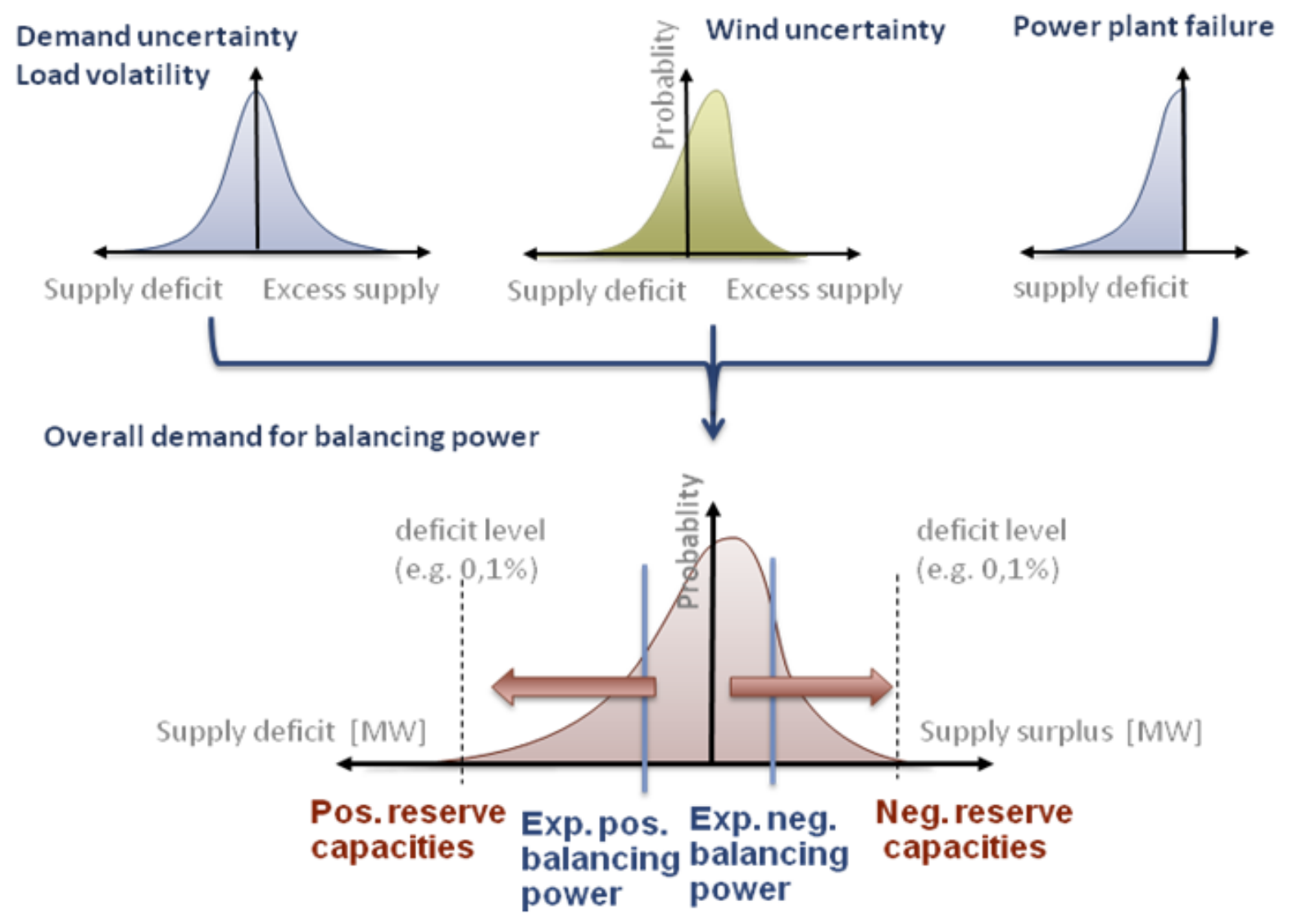

\subsection{Improve the accuracy of wind forecasts}

The accuracy of the wind power forecast has significantly improved in recent years. In Germany, the $24 \mathrm{~h}$ forecasting error ${ }^{4}$ for the aggregate output from German wind turbines was significantly reduced from $6.1 \%$ in 2007 to $5.6 \%$ in 2008 (Von Roon and Wagner, 2009). Future improvements of wind forecasting can be obtained based on improvements of the available wind models as well as their coupling. Further improvements of wind models will lead to an increase in forecasting accuracy in the coming years. The German DENA II study (DENA, 2010) predicts forecast errors onshore might be reduced by as much as $41 \%$ by 2020 .

Despite this expected improvement in wind forecasts, the DENA grid study (DENA, 2005 and Bartels, 2006) shows that the uncertainty about predicting the absolute volume of wind output

\footnotetext{
${ }^{3}$ Similar to DENA (2005).

${ }^{4}$ Root mean squared error (RMSE) of the total installed capacity
} 
day-ahead will increase as wind penetration grows. Thus the demand for positive and negative balancing power, primarily for the time frame $>15$ minutes will likely increase if the current power market designs are maintained (Figure 2$)^{5}$. In short, improved wind forecasts alone will not be enough to reduce uncertainty sufficiently - we need to consider other options for reducing or managing uncertainty.

Figure 2: Increasing wind uncertainty depending on the forecast horizon for Germany and three transmission zones ${ }^{6}$.

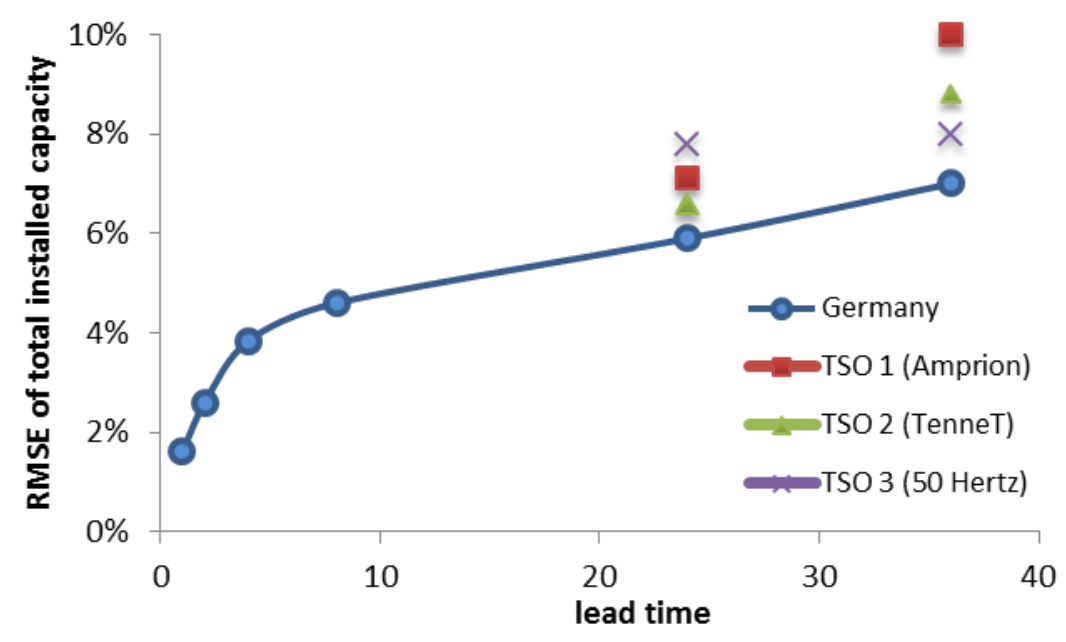

\subsection{Reduce the lead-time for wind forecasts through intraday markets}

The lead-time of wind forecast strictly determines forecast accuracy. When the wind forecast changes from a day-ahead forecast to an intraday forecast with a 1-4 hour lead-time, the errors decrease drastically. Figure 2 displays the percentage of the total installed capacity for a 1-,2-,4,8- hour and day-ahead forecast for Germany in 2008. The average forecast error (RMSE) is reduced to $3.8 \%$ of the installed capacity compared to $5.9 \%(7.0 \%)$ of the $24 \mathrm{~h}$ (36h) day-ahead forecast. (Smeers, 2008; Von Roon and Wagner, 2009)

\subsection{Average wind output over larger areas}

Large wind areas can reduce uncertainty in the overall wind feed-in. The correlation of wind feed-in and uncertainty strongly depends on the distance between wind farms (Figure 3) and therefore also on the size of the investigated area. This effect can be observed even for

\footnotetext{
${ }^{5}$ Source: Own graph, with data from Hasche B. (2007) and Von Roon and Wagner (2009)

${ }^{6}$ Estimation for Germany based on Von Roon and Wagner (2009), DENA II (DENA, 2010)
} 
significantly large areas. The integration of the German transmission system operators (TSOs) into one market in 2009 provided a good example. The day-ahead (24h) forecast error (RMSE) for each of the four TSOs was between $6.6 \%$ and $7.8 \%$. Bundling the region reduced the forecast error to $5.9 \%$ (Figure 2).

Figure 3: Correlation of two wind parks depending on the distance of the wind parks and time of forecast. $^{7}$

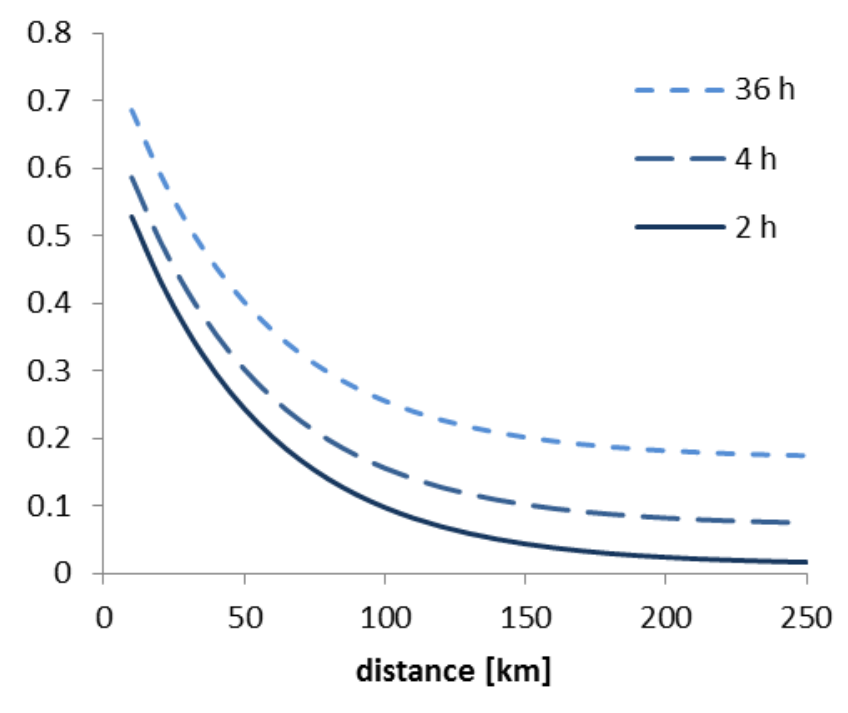

This paper focuses on these last two opportunities and thus investigates the institutional perspective: reducing lead time through 1 ) intraday markets and by 2 ) increasing the size of wind areas.

\footnotetext{
${ }^{7}$ Graph: Own. Calculations based on formula and data from Hasche B. (2007).
} 


\section{$3 \quad$ Flexibility of the power system to deal with the uncertainty}

In addition to the opportunities to reduce wind uncertainty described in Section 2, uncertainty will remain a decisive part of the system and the power system offers means of flexibility to address uncertainty. The power system can respond to deviations between demand and supply by adjusting demand, adjusting supply, or using storage capacity. Three factors determine the flexibility of the power system to respond to uncertainties.

\subsection{System flexibility increases with increasing lead time}

The lead time that is available to pursue system adjustments determines the generation and demand technologies that can respond. Within the one hour timeframe, the system offers three types of response: primary response is available to match unpredicted deviations in time frames from 30 seconds to 15 minutes, secondary response is available within 5 minutes and tertiary response requires lead times from 15 minute to 1 hour. Only gas turbines, hydro plants, and pump storage have the technical capacity to provide a full start within 15 minutes. Coal and nuclear power stations must already be operating on part load to be able to contribute shortterm responsiveness.

With lead times of one hour to four hours it is possible to start-up combined cycle gas turbines and coal power stations, but longer lead times are necessary to start up nuclear power stations. With increasing lead-time more types of generation assets are available to adjust their output.

\subsection{Interaction between balancing and energy markets influences system flexibility}

Many generation assets can only adjust their output close to real-time, if they are already operating (nuclear, lignite, coal, and certain gas power plants). Only the plants that are operating can provide negative balancing reserve, while these plants have to operate in partload to be able to provide positive balancing power ${ }^{8}$. Moreover, a power plant is only willing to decrease its energy sales to provide reserve capacities for balancing markets if the expected price it gets for actually providing those reserves is able to compensate for the foregone margin (price minus marginal cost) in the energy market.

\footnotetext{
${ }^{8}$ Power plants such as gas turbines that can provide positive balancing power with a cold start of the turbine often face high variable cost of operation.
} 
Adjustable capacity is therefore highly dependent on the commitment of conventional generation units as part of energy sales in day-ahead and longer-term markets and the ability to adapt this day-ahead commitment to the changes in the market within the last $24 \mathrm{~h}$ before physical dispatch. Therefore, when information on the wind-output increases during the day, reserve capacity no longer required in the balancing market must be made accessible within the intraday electricity market. At the same time it must be possible to react to changes in the electricity market by changing reserve capacities to suppliers that are no longer needed and able to offer their capacity to the balancing markets at lower costs.

Market design needs to allow generators to adjust their energy production and provision of balancing services in a joint bid, so that they can contribute to an efficient system operation.

\subsection{Interaction with transmission constraints}

In the current European power market designs, transmission capacity is usually allocated for long-term and day-ahead energy sales. Some transmission capacity is reserved to ensure system stability in the case of unexpected failures of power stations and transmission equipment. Only in limited instances, however is it possible to re-schedule power flows between countries during the day. This creates a constraint for intraday optimisation of the power system - focusing on the generation capacity that is locally available rather than using the capacity that is distributed across the entire system. As seen above, the closer to real time the scheduled output of generation has to be adjusted, the fewer generators are available that can provide flexible capacity. This increases the costs of dealing with uncertainty, compared to a coupled reserve and capacity markets, because less suitable generators have to be selected.

In addition, with fewer generators providing flexibility, the likelihood that they can exercise market power increases. This results in distorted prices, which increases costs and potentially creates inefficiencies in the process of balancing the system. Options to increase supply of flexibility within a region are limited, though we can consider ways to enlarge the region and pool of potential players. A coupling of national balancing markets will then again increase market efficiency and reduce potentials to exercise market power. 


\section{$4 \quad$ The challenges for the current power market system}

The current EU power market designs are analysed here to assess how well they make use of the opportunities to limit wind forecast uncertainties that were identified in section 2 and of the technical flexibility to deal with these uncertainties identified in section 3 . Three specific questions translate into six criteria for assessing whether power markets make use of opportunities to reduce wind uncertainty and leverage power system flexibility:

\section{Does the market design make full use of information as it becomes more accurate during the} day?

1. Can power system dispatch be adjusted during the day? (Section 4.1)

2. Can the requirements for, and providers of, balancing services be adjusted during the day? (Section 4.2)

\section{Will all actors that can technically respond be fully included?}

3. Are the current power market designs suitable for power stations that can only operate for several hours at a time, and might thus be excluded in systems where bids are submitted hour by hour? (Section 4.3)

4. Does the international integration of energy markets facilitate the provision of flexibility by actors in neighbouring countries? (Section 4.4)

5. To what extent do incentives and systems exist to make full use of the flexibility provided by the demand side? (Section 4.5)

\section{How transparent is the market?}

6. Is it necessary and possible to identify and monitor the potentials and exercise of market power? (Section 4.6)

\subsection{Intraday adjustments to reduce wind forecast uncertainty in balancing markets}

Traditionally, power markets focused on long-term contracting between demand and supply and provided a platform for day-ahead trading (power exchanges) to match demand and supply. Any deviations between demand and supply contracted at the day-ahead stage and subsequently realised were adjusted by the system operator with energy from the balancing market. Figure 4 illustrates the provision and actual use of balancing energy in a market without intraday trading. In this example, the day-ahead forecast in $\mathrm{t}-24$ underestimates the actual wind load in t0. The TSO must contract positive and negative capacity reserve for balancing at the 
level of wind forecast uncertainty that persists in $\mathrm{t}-24$. In the example in figure 4 , the provision of reserve and response capacity is unable to adapt to improved forecasts. In $\mathrm{t}-1$, large amounts of positive and negative balancing reserve capacities still have to be withheld from the market. The deviation of wind output from day-ahead forecasts is then balanced close to real-time within the last hour before dispatch $(t)$.

Figure 4: Example I - Wind forecast uncertainty, actual wind feed-in, and balancing services in a market without intraday trading.
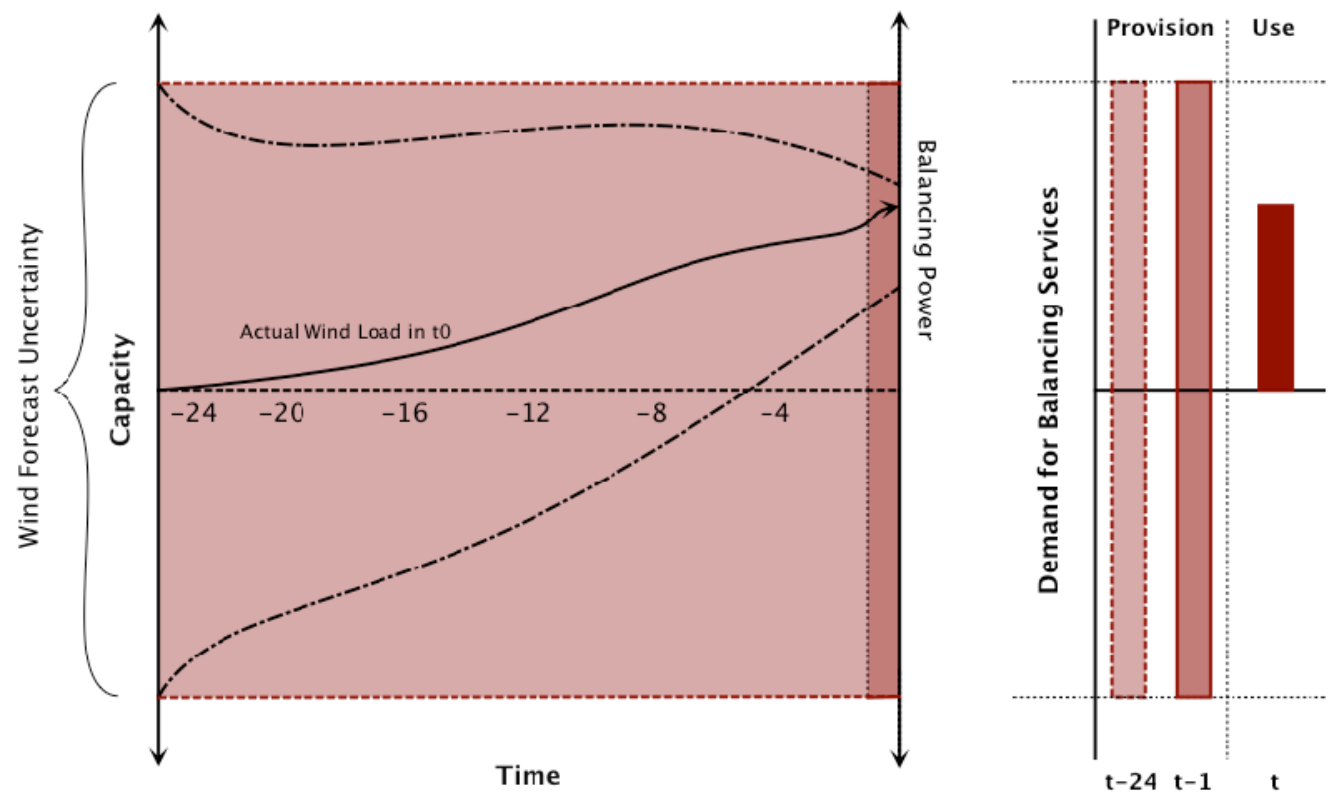

During the day, the improved wind-forecast estimates a higher supply of wind for the specific hour to. With the improved wind forecast, the expected deviation and demand for positive and negative balancing capacity also decreases (dotted line). Recognizing this benefit, various European countries have established intraday markets to allow for an adjustment of dispatch during the day. Still, there is a large variety of power market designs, some more effective than others, and whose differences make it difficult for inter-region market coordination.

In the UK, all generators, including wind turbines, have to submit their final schedules to the TSO half an hour before real time (gate closure time). Any resulting or subsequently emerging deviations between demand and supply are managed by the TSO. Thus, market participants can, in principle, use bilateral trading and power exchanges for intraday adjustments. In practice, however, all wind turbines are owned by or managed as part of the portfolio of incumbent generators and most intraday adjustments and pooling of uncertainties are pursued within this limited portfolio rather than across the power system. 
In Germany, the responsibility for balancing wind output is allocated to the TSO. The joint ownership of many TSOs with generation companies providing balancing services created incentives to maximise the acquisition of costly balancing services, as costs can be passed to consumers through network charges.

Until 2008 wind uncertainty could not be traded in the intraday market. Weber (2010) also points out that liquidity in the intraday markets was small. Starting in 2009, however, TSOs have been required to also use the intraday market for procurement of services to balance the uncertainty of wind forecasts. As a result, the improved forecast accuracy during the day now allows the TSO to trade deviation in wind forecast from the day-ahead forecast in the intraday market (See Figure 5). Demand for balancing power in t decreases to the deviation between the forecast in $\mathrm{t}-1$ and physical supply in $\mathrm{t}$. At the same time the volume of positive and negative balancing services that have to be contracted day-ahead reduces to the wind uncertainty between $\mathrm{t}-1$ and $\mathrm{t}$.

Figure 5 indicates that these improvements in market design lead to less demand for overall reserve capacities. In addition, part of rescheduling of the power plants necessary to cope with wind uncertainty is shifted from balancing markets towards the, in general, more flexible intraday market. Since 2009 the liquidity in the intraday market significantly increased, due to the demand from TSOs. ${ }^{9}$

Spanish wind generators have two ways of being remunerated ${ }^{10}$ (Royal Decree RD 661/2007 and de la Fuente, 2010): through a regulated feed-in tariff regime or by being paid a premium over the day-ahead price. In the first case they are paid a fixed price of $€ / \mathrm{MWh}$ times the produced energy. In the second case they are paid a premium over the day-ahead price times the produced energy as long as the resulting price is between a floor and a cap price. Wind generators must remain at least one year in the chosen regime, although arbitrage between the regimes has been reported. The wind generators in both regimes must submit a production program to the TSO at gate closure of the day-ahead and intraday markets ${ }^{11}$. In the case of deviations, wind generators are penalized according to specific formulae for both regimes ${ }^{12}$.

\footnotetext{
${ }^{9}$ The question of Weber (2010) remains: are intraday markets sufficiently liquid at all times? Therefore can a capacity market, such as the balancing market, be fully replaced by energy-only markets (as it is the case of intraday markets).

${ }^{10}$ Wind generators operating prior to 2007 can also be remunerated according to a specific regime defined in the Royal Decree RD 436/2004 until 2012, in which year they must choose one of the regimes described in the main text.

${ }^{11}$ However, the TSO uses its own wind generation forecast software for operational purposes

${ }^{12}$ Specifically, wind generators in the feed-in tariff are not penalized if deviation is less than $20 \%$ of the forecast. If this figure is exceeded they pay a penalty proportional to the amount of the deviation. Wind generators in the
} 
The TSO operates six consecutive intraday clearing auctions that allow for a full rescheduling of power plants and optimisation of the system in line with information about demand and supply balance. In addition, as all interactions are focused on six intraday auctions, they exhibit more liquidity than observed in other European markets with continuous intraday trading. This market solution has allowed the TSO to keep the volume of required balancing services constant in the last years, despite the large penetration of wind power in Spain and the limited interconnection with neighbouring countries.

Figure 5: Example II - Wind forecast uncertainty, actual wind feed-in, and balancing services in the German market setup with intraday trading.
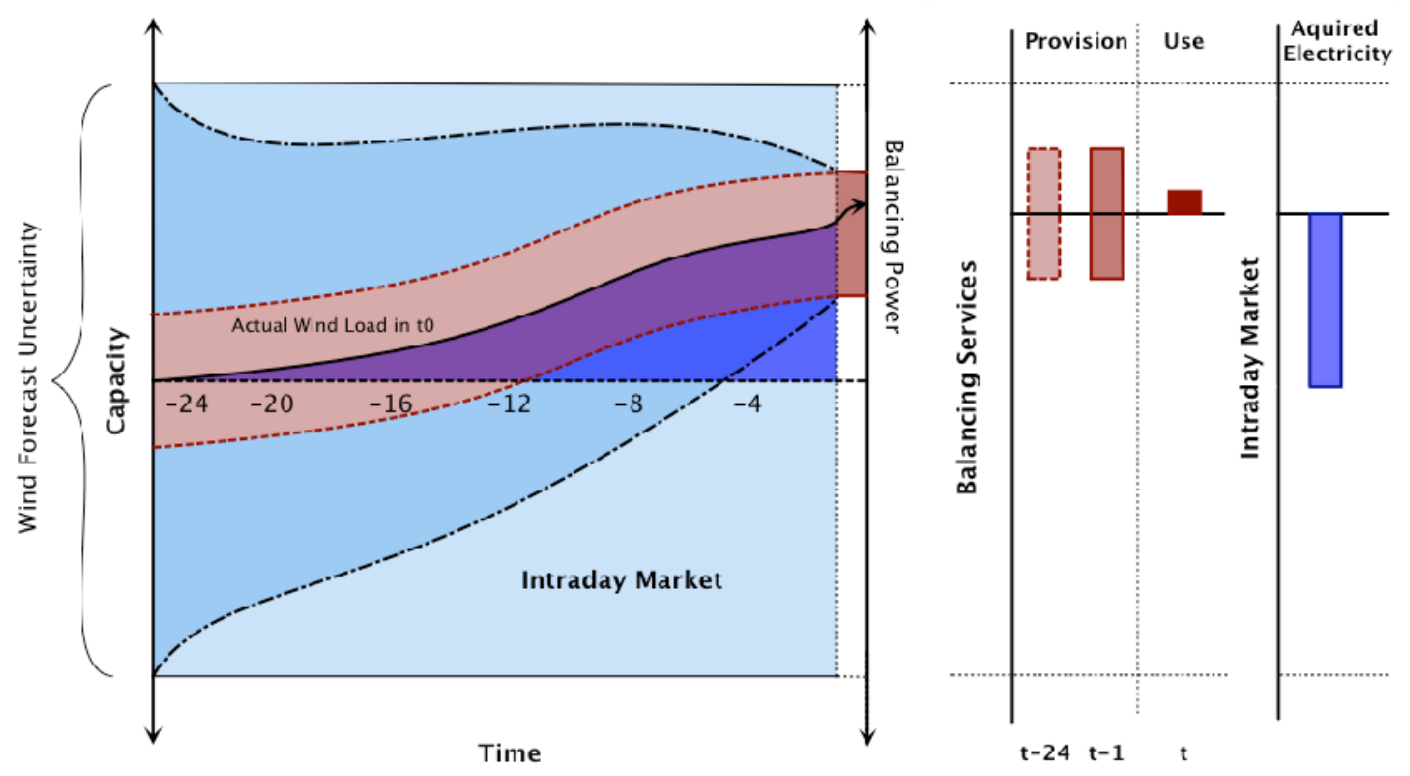

Key issues with the current EU system related to intraday trading: market liquidity, regulatory framework and transparent wind forecasts.

1. Liquidity of the markets

The key concern when implementing intraday markets is whether both balancing and intraday markets can remain sufficiently liquid. Markets are defined as liquid if the number of bids and the amount of trading activity is high enough to create transparent prices and ensure that individual actors only have small impacts on the price formation. In 2010 Weber (2010) pointed out that intraday markets might not be an improvement per se due to a lack of liquidity. Using

premium regime pay a penalty in the case that their deviation is against the system deviation and a zero penalty otherwise, according to formulae similar to those used in most European systems. 
trading volume in a market as the indicator for liquidity, Weber finds that for 2008 the intraday markets in Germany and other selected countries were not sufficiently liquid. Starting in 2009, TSOs in Germany have been committed to balancing their procurement for uncertainty of wind forecasts through the day-ahead and intraday market, and the liquidity of the intraday markets substantially improved when this new market setup was implemented.

\section{Regulatory framework to support TSOs in intraday adjustments}

If TSOs are responsible for balancing deviations of intermittent generation from output, as they are in Germany, a clear regulatory structure is required. One approach is the use of incentive schemes, which expose the TSO to some of the costs for system balancing (or sharing profits from savings on balancing costs). Thus the TSO would be motivated to reduce costs that would otherwise be fully passed on to consumers.

The U.K. has successfully applied incentive schemes for the TSO to minimise system balancing costs (not related to wind which is privately balanced). This has created three sets of difficulties. First, to maximise long-term benefit from future negotiations of incentive schemes, the TSO has had strong incentives to improve its bargaining position by limiting transparency. Second, generators in the UK have complained about non-transparent contracting choices by the TSO, reducing trust and certainty. Such sentiments undermine efforts to integrate wind power into the dispatch of power systems and to provide transparent information for planning and permitting processes of transmission expansion. Third, the U.K. is an island, so incentives for NGT (the national TSO) have limited impact on neighbouring TSOs. In the case of continental European TSOs, incentives to minimise balancing costs for individual TSOs could lead to behaviour that shifts costs and responsibility to neighbouring countries at the expense of system efficiency and security.

With difficulties relating to incentive schemes on TSOs, the regulatory solution is a combination of (i) minimising exposure to market outcomes, e.g. through clear unbundling of system balancing obligations from other business activities, and (ii) providing clear rules for as many decisions as possible, while retaining the level of discretion necessary to allow responses to unexpected system circumstances. As bilateral contracting is in its very nature based on discretionary choices associated with each negotiation, auctions have become the preferred market interface in such environments. The Spanish example is a starting point, and many power systems in the US (e.g. PJM) have further refined the approach and use rules that are guided by the technical constraints of the system. 
3. Transparent and accessible wind forecasts

Spain implemented an RES control centre (CECRE) that overlooks the wind feed-in and provides aggregated forecasts for the coming 48 hours. All wind farms exceeding $10 \mathrm{MW}$ must be connected to this control centre and provide continuous information on status and actual feedin. Additionally, CECRE bundles a variety of long term forecasts (up to 10 days) and detailed forecasts for the next 48 hours. This allows for clear market monitoring of installed wind power and for a high penetration of special regime generation in the system, which ensures security of supply. CECRE has the ability to centrally trigger wind curtailment in times of need.

\subsection{Joint provision of energy and balancing services}

Energy and balancing services are both provided by power stations; decisions about one affect the other. For example, a power station that is operating at full capacity cannot provide upward balancing services and a power station that is not operating cannot provide downward balancing. Furthermore, for most power stations it takes time (minutes to hours) to get started, and in these cases only power stations that are providing some power can also offer balancing services.

Generation companies therefore have to jointly decide on their provision of energy and reserve and response services to the market; they must coordinate these services between spot, intraday, and balancing markets. If it is likely that upward balancing energy will be required, it might be efficient to operate coal power stations on part load so as to provide that service. If the likelihood is lower, it might be (at times of low coal and CO2 prices) be cheaper to operate one coal power station at full load, and start up a gas power station if required.

In the past, this was of limited concern. Usually the demand-supply balance did not change very much between different weekdays, so actors in the market could learn from the realisation in previous days so as to optimise their choice. With increasing penetration of wind power, however, the net demand for energy (demand - wind output) and the demand for balancing services will vary from day to day; coordination to reach an efficient market equilibrium (many local equilibria may exist due to non-convexity of unit commitment choices) is more complex. 


\section{Key issue with the current EU system: Ability to optimize between balancing and energy markets.}

The main difficulty for market actors is that in most European power markets, power-plant owners must commit their capacities day-ahead either to spot/intraday trading or to balancing services. Changing this commitment closer to real-time is not possible. Smeers (2008) points out that the current designs of day-ahead, intraday markets and the balancing system in the EU are based on three different organizational schemes. Smeers argues that "these multiple arrangements violate the finance view that day-ahead, intraday and real-time are just different steps of a single trading process and hence require a single trading platform."

Table 1 shows the current market implementation in Germany. It must be pointed out that even though TSOs trade in the intraday market, the power plants contracted to be available for the provision of balancing services (for power plant failure and wind uncertainty between $\mathrm{t}-1$ and t0) cannot be changed. The primary reason is that an intraday market for reserve capacities is missing.

An increasing wind feed-in will lead to a reduction of conventional power generation. The power plants that offer to reduce electricity supply, e.g. through part-load operation, would be able to provide positive balancing power for the same hour at a very low cost but will in practice be unable to provide their services due to the given market design. Instead, balancing availability is likely to be provided by units with low day-ahead capacity costs (gas turbines) and high variable costs, resulting in subsequent increases in balancing costs. 
Table 1: Market actors and traded products in reserve and response markets ${ }^{13}$.

\begin{tabular}{|c|c|c|c|c|c|}
\hline & & & \multicolumn{3}{|c|}{ Time of Trade } \\
\hline Type of Market & Traded Products & Market Actor & Day-ahead & Intraday & Real-time \\
\hline \multirow{2}{*}{$\begin{array}{l}\text { Markets for reserve } \\
\text { capacities }\end{array}$} & $\begin{array}{l}\text { Wind uncertainty in t-1 until t and } \\
\text { real-time }\end{array}$ & TSO & \multirow{2}{*}{$\begin{array}{l}\text { Day-ahead } \\
\text { balancing } \\
\text { market }\end{array}$} & \multirow{2}{*}{$\begin{array}{l}\text { No trading of } \\
\text { balancing } \\
\text { capacities }\end{array}$} & \multirow{2}{*}{$\begin{array}{l}\text { Real-time } \\
\text { dispatch of } \\
\text { balancing } \\
\text { power }\end{array}$} \\
\hline & $\begin{array}{l}\text { Reserve capacity for power plant } \\
\text { failure, demand forecast uncertainty } \\
\text { and intra-hour load volatility }\end{array}$ & TSO & & & \\
\hline \multirow{3}{*}{ Electricity markets } & Wind uncertainty in t-24 until t-1 & TSO & \multirow{3}{*}{$\begin{array}{c}\text { Day-ahead } \\
\text { spot } \\
\text { market } \\
\text { trading }\end{array}$} & $\begin{array}{l}\text { TSO trades in } \\
\text { intraday market }\end{array}$ & \\
\hline & $\begin{array}{c}\text { Unforeseen power plant outage } \\
\text { (after t-4), deviations in the supply } \\
\text { schedule }\end{array}$ & Producer & & Trading & \\
\hline & Intraday changes in demand & Industry & & Trading & \\
\hline
\end{tabular}

At present it appears to be difficult to implement an intraday market that efficiently processes both energy and bids for balancing capacity. The difficulties arise primarily because balancing services are acquired by the TSOs, while electricity in spot and intraday is traded on the power exchange and bilaterally. Alternative options for joint provision of energy and balancing/intraday services are:

- A fully bilateral market that allows actors to jointly trade energy and balancing services. It is difficult, however, to see how market participants could match their supply/demand to a complex set of energy/balancing products with specific temporal and spatial requirements.

- Pool type trading arrangements. These centralised market systems facilitate joint trading through joint optimization, as is the case in all the U.S. ISO markets such as in $\mathrm{PJM}^{14}$. Intraday market clearing platforms in the PJM system differ from the bilateral approach in current European intraday trading schemes. The system operator calculates close to real-time an optimal dispatch based on firm schedules submitted and flexible bids provided by market participants. These bids can include technical parameters like ramp rates and part load constraints to allow the system operator to make full use of the available generation assets. This approach ensures high liquidity for short-term optimization of the system. Day-ahead (and intraday) markets are

\footnotetext{
${ }^{13}$ Graph is based on the German market design (own graph).

${ }^{14}$ One of the largest electricity market systems in the U.S. comprising all or parts of 13 states and the District of Columbia.
} 
pursued using the same market-clearing algorithm for dispatch and transmission allocation. This creates inter-temporal consistency and avoids gaming otherwise often observed between day-ahead and shorter term markets. Operating reserves and energy are co-optimized, and start-up and minimum load costs are considered in the optimization and can be recovered through side payments if market revenues are insufficient. While long-term contracting remains bilateral, most day-ahead and intraday activity is pursued on the centralized platform of the independent system operator (ISO) and not bilaterally as is the case in most European markets.

Figure 6: Joint optimisation of balancing capacities and intraday trading (EWI).
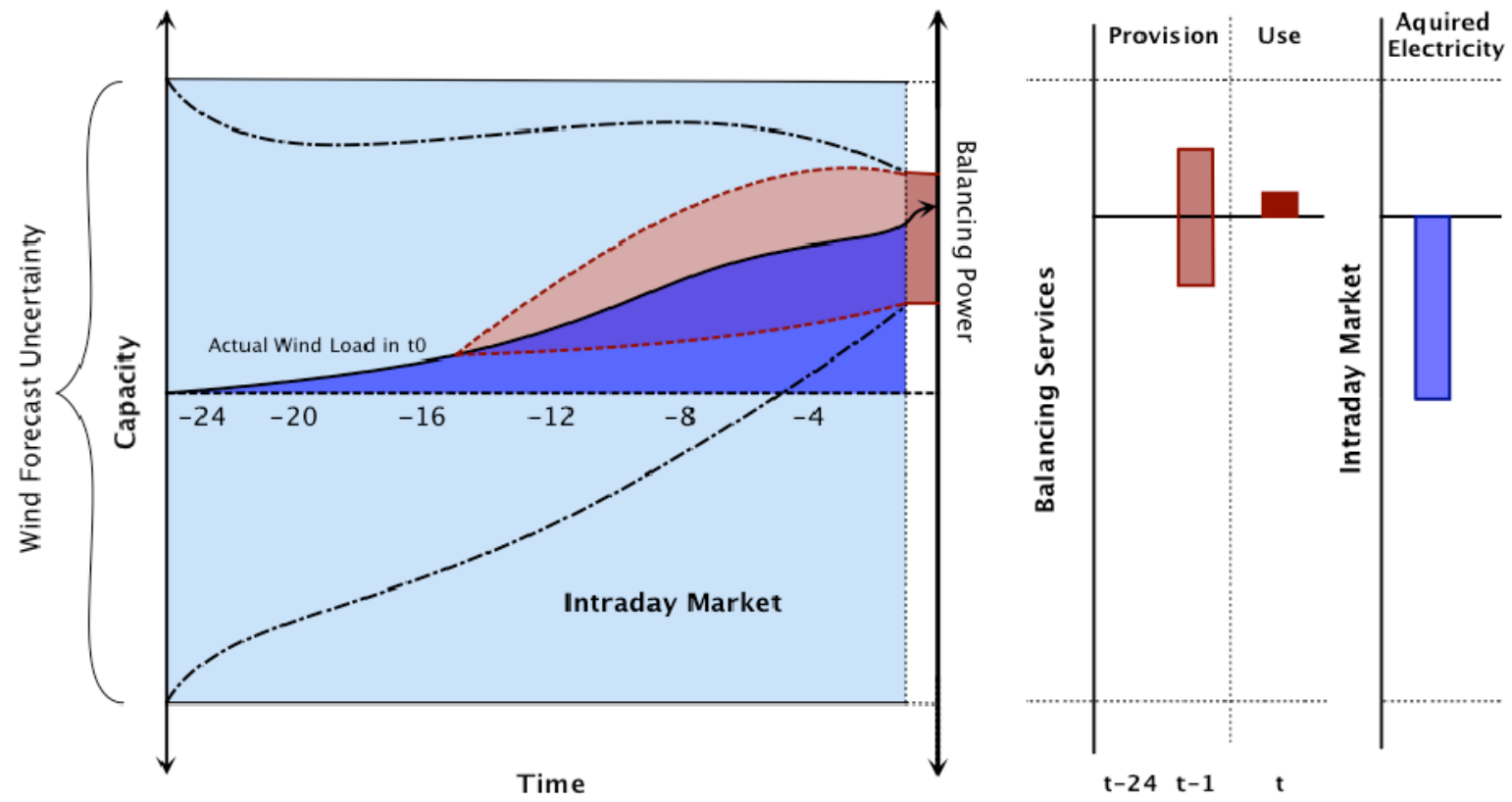

\subsection{Joint provision of power across multiple hours}

In general a system optimisation (efficient market outcome) occurs if generation companies can offer bids that combine offers for their production for individual hours. However, power stations require time and incur energy and other costs to be started up. As a result, generation companies cannot make decisions on the operation of the power station for individual hours, but have to consider interactions across hours instead. This allows for an efficient choice to operate a gas-peaking plant at short-demand peaks of one hour, and to start up other plants if demand is high for longer times. 


\section{Key issue with the current EU system: Inter-temporal optimisation of start-up and shut-down of power plants.}

In systems with large hydro components, like in Scandinavia, start-up costs are of limited concern and inter-temporal optimisation is therefore of less relevance.

In other systems, market participants/market places have developed methods to submit a few specific block bids, e.g. to provide energy during day-time periods, or to submit ramp-rate, start-up, and other constraints as part of their bid, as in U.S. ISO markets ${ }^{15}$. The system of specific block bidding has worked relatively well as long as it was possible to identify a block of hours for which demand will be higher. With increasing penetration of wind power, however, this situation will change, and the net demand (demand minus production of wind output) will not follow a strict pattern.

The EU needs systems that can reflect inter-temporal dependencies in the production of power in order to find efficient market outcomes ${ }^{16}$. Market designs across the US (PJM, NY-ISO, Texas, California) have evolved so as to allow generators to submit complex bids that reflect start-up costs and times, ramping constraints, and energy costs. Based on this information, the market clearing algorithm selects the most suitable set of power stations to provide energy and system services.

\subsection{Capturing benefits from international integration of power systems}

Larger regions reduce the overall demand for balancing and reduce costs for providing balancing power through a broader portfolio of power plants and additional sources for balancing power. However, larger regions also include more potential transmission constraints that need to be considered.

In some instances this might imply that at times when transmission lines are congested in one direction, no upward balancing services can be provided in this direction. At the same time,

\footnotetext{
${ }^{15}$ Ockenfels et al. (2008) suggest that the pool type market models with their central organisation, might allow in particular the close co-ordination and synchronisation of generation, transmission, and balancing energy. They might be advantageous if competition is strong, they can be regulated effectively and the deficits of a centralised system optimisation, which always occur in practice, can be kept small.

${ }^{16}$ Nabe (2006) points out, that for an efficient integration of wind energy, the short term markets must be able to cope and process more information especially with regard to inflexibility of conventional power plants. He proposes that: conventional power plants should be able to use bid arrays consisting of prices and technical information (ramp rates, minimum load, etc.) and Nabe (2006) points out, that such complex bids can only be processed by a centralised market mechanism.
} 
however, twice the volume of transmission capacity can be used to provide upward balancing services in the opposite direction (against the prevailing energy flow). This might be more valuable, because in a region with lots of wind output, only limited amounts of thermal generation capacity are operating and the region would therefore be in a position to provide balancing services and upward response capacity. In contrast, the importing country is likely to have more thermal capacity operating and is therefore potentially better suited to provide upward balancing services from this capacity. ${ }^{17}$

\section{Key issue with the current EU system: Integration of congestion management with day-ahead and intraday energy and ancillary service markets.}

By using the potential to trade balancing and intraday electricity against the flow of transmission lines or reserve transmission capacities for intraday trading, the integration of congestion management and energy and ancillary service markets can enhance the value of the transmission network and reduce system operation costs. A complementary paper on congestion management discusses the value of an integrated energy and transmission market (Neuhoff et al., DIW Discussion Paper 1161, 2011).

Current power market designs focus on an integration of energy and transmission markets at the day-ahead stage. As outlined in this paper, the intraday market is of equal importance, and the value of the flexibility provided by the transmission system increases closer to real time. Therefore a consistent approach is necessary that also facilitates integration of intraday energy and transmission markets ${ }^{18}$. The U.S. power market designs offer a possible solution. The market designs have succeeded in integrating energy, ancillary service, and balancing markets at day-ahead and intraday stages by using the same market-clearing algorithm for dispatch and transmission allocation for all markets.

\subsection{Integration of demand side into intraday and balancing markets}

Market liquidity can be increased if all market actors (not just conventional power plants) capable of providing intraday and balancing services can enter the market. Demand side management (DSM), and renewable energies especially, have the technical potential to provide their services to the market. At present, however, only a small share of demand side

\footnotetext{
${ }^{17}$ The effect is even stronger where the importing country is using the imported energy to store water, a process that can be easily interrupted with very short response times.

${ }^{18}$ Newberry (2009) points out that the TSOs are subject to national regulation and therefore efficient cross-border transactions depend on the national regulation as well as the interplay between the various regulators involved.
} 
management is actually integrated into the markets. DSM technologies (such as reduction of electricity demand) face low costs for providing reserve capacities, especially for positive balancing power, and work well for circumstances where the probability that those reserve capacities will be used is low. ${ }^{19}$

Nordpool introduced a harmonization of balance regulation in $2009^{20}$. The new regulation lowered the bid size to $10 \mathrm{MWh}$ to explicitly encourage demand side management The implementation of automatic activation for bids could further reduce the minimum bid size, (Von Roon and Wagner, 2009) thus providing greater incentives for non-conventional generation such as DSM to enter the market. Denmark introduced such a system in May 2008, and other Nordpool countries are following.

In 2007 in Germany, no DSM-potentials were prequalified and were thus unable to participate in the balancing market. An improved market design in 2008 allowed DSM technologies to provide balancing services in the minute reserve market. One aspect of the improved market design was the introduction of a day-ahead auctioning of minute reserve capacities and a reduction of the minimum capacities for prequalification to $15 \mathrm{MW}$. Energy intensive industries made use of their DSM-potentials and provided approximately $20 \%$ of the hourly demand for reserve capacities in the tertiary balancing market. In the secondary reserve market, technologies have to commit their balancing potentials on a monthly basis. DSM technologies, however, strongly depend on the downstream production process. A monthly pre-commitment cannot be met by most players with potential DSM technologies.

DENA (2010) shows that demand side management has the potential to provide reserve capacities for balancing power. ${ }^{21}$ Demand side management might further provide load shifting from peak to off-peak and low-wind to high-wind periods.

\section{Key issue with the current EU system: Incentives and access for demand side participants.}

Tight access rules still prevent large potentials of DSM from engaging in balancing and intraday markets. One pertinent criterion to market access is the lead-time and duration of a precommitment to the reserve and balancing markets. Only a day-ahead auction provides

19 Therefore DSM-Potential corresponds to the left and right ends of the probability function in figure 1, while conventional power plants are ideal to serve the balancing demand close to the origin of the probability function. ${ }^{20}$ See also Nordel (2008).

21 Today economic potential for demand side management stems from large industrial processes that serve as emergency capacities and are only rarely used. With decreasing costs for Smart-Meter and boxes and through bundling a large share of processes future DSM potential will become available in the tertiary sector starting from 2015 and later on in the household sector. 
sufficient incentives for DSM and renewables to participate. In addition, a reasonable market design must be implemented that allows small units to engage in the market.

The US experience suggests that demand side investment follows once a market design is implemented that provides a long-term, credible framework and justifies the added cost of time and capital.

\subsection{Monitoring of market power}

The closer to real time that energy and balancing services are traded, the fewer the participants with the necessary technical flexibility and organizational capacity to participate in the market, which leads to greater market power for these participants and higher prices. With growing penetration of wind power, re-adjustments to the power system will be increasingly necessary during these hours close to real time and will amplify these circumstances of limited competition.

To avoid exposure to the very short-term market power of generators, system operators acquire a significant share of the balancing services in day-ahead and longer-term auctions. Multiple contracting rounds reduce, but do not eliminate, the ability of generators to exercise market power. However, this approach can preclude optimization across the provision of energy and balancing services and intraday adjustment.

In the mid-term, more power will be traded within the last 24 hours before delivery, and it will therefore become increasingly important to monitor the bids so as to control the exercise market power in these markets. The exercise of market power not only results in rent transfers to generators, but also distorts the price signal and thus creates inefficiencies that increase the cost of system operation and might provide misleading signals for investment choices.

\section{Key issue with the current EU system related to monitoring market power: availability of transparent information, ability to evaluate bid price, and capacity to perform market power analysis.}

1. Availability of transparent information on bids and state of the system.

The identification of potential market power abuse requires access to information on bidding prices as well as a detailed record of the state of the power system. 
2. Ability to evaluate whether bid prices are appropriate.

In energy-only markets that do not use the marginal bid to determine the market-clearing price (e.g. bilateral energy markets), market participants adjust their bid to reflect the scarcity value of generation. In this case it is difficult to differentiate between competitive and strategic bidding behaviour. Markets (e.g. current power exchanges) where the marginal bid determines the clearing price allow generators to submit bids at short-run cost, and are thus more suitable for market power monitoring.

However, generators that face inter-temporal constraints cannot offer power for only one hour and might therefore adjust their bids to reflect start-up costs and other constraints. Thus, it is difficult to assess whether the bid prices are competitive, which constrains the ability for effective market power monitoring. The approach in most U.S. markets, in contrast, allows generators to submit complex bids containing start-up costs and ramping constraints in addition to variable generation costs, such that all parameters can be assessed independently.

3. Institutional capacity to perform market power analysis

For an effective market power monitoring, an independent institution must have access to all relevant market information and must be equipped with the analytic capacity to provide an hour-by-hour analysis of the reserve and response markets. As the power system and many of the power generators are integrated across European countries, close cooperation or an integrated approach across Europe is necessary.

\subsection{Summary of requirements for a future EU power market design}

The EU power systems offer large technical flexibility, which allows for the use of improved forecasts to limit the impact of wind uncertainty. Table 2 summarises how the different power market designs currently implemented across Europe satisfy the criteria that emerge from this requirement. It also illustrates that the power market design that has become standard in the U.S. markets, such as PJM, offers the opportunity to satisfy all six criteria.

While long-term contracting remains bilateral, most day-ahead and intraday activity is pursued on the centralized platform of the independent system operator (ISO) and not bilaterally, as is the case in most European markets. This allows the system operator to calculate at close to real-time an optimal dispatch based on firm schedules submitted and flexible bids provided by 
market participants, incorporating various technical parameters, such as start-up costs and ramp-up times, allowing for inter-temporal optimization for all plants.

Table 2: Summary of power market designs performance against criteria.

\begin{tabular}{|c|c|c|c|c|c|c|}
\hline & $\begin{array}{l}\text { Dispatch } \\
\text { adjusted during } \\
\text { day }\end{array}$ & $\begin{array}{l}\text { Balancing } \\
\text { requirements/ } \\
\text { provision adjusted } \\
\text { during day }\end{array}$ & $\begin{array}{l}\text { Flexible use of } \\
\text { individual } \\
\text { conventional } \\
\text { power stations }\end{array}$ & $\begin{array}{l}\text { International } \\
\text { integration of } \\
\text { intraday/ } \\
\text { balancing } \\
\text { markets }\end{array}$ & $\begin{array}{l}\text { Integration of } \\
\text { demand side } \\
\text { response }\end{array}$ & $\begin{array}{l}\text { Effective } \\
\text { monitoring of } \\
\text { market power } \\
\text { possible }\end{array}$ \\
\hline UK system & $\begin{array}{l}\text { Liquidity in } \\
\text { bilateral market } \\
\text { low, so utilities } \\
\text { pursue internal } \\
\text { balancing and } \\
\text { hold excessive } \\
\text { reserves }\end{array}$ & $\begin{array}{l}\text { Difficult to find matching } \\
\text { partners for trade }\end{array}$ & $\begin{array}{l}\text { Only within portfolio } \\
\text { of utility; difficult to } \\
\text { find matching } \\
\text { partner(s) that } \\
\text { buy/provide energy } \\
\text { matching demand/ } \\
\text { technical constraints }\end{array}$ & $\begin{array}{l}\text { Difficult due to } \\
\text { separate energy } \\
\text { and transmission } \\
\text { markets; illiquid } \\
\text { markets for both } \\
\text { products intraday }\end{array}$ & $\begin{array}{l}\text { No system- wide } \\
\text { optimisation }\end{array}$ & $\begin{array}{l}\text { Difficult } \\
\text { because prices } \\
\text { bundle energy, } \\
\text { scarcity, and } \\
\text { start-up cost }\end{array}$ \\
\hline German system & $\begin{array}{l}\text { To some extent, } \\
\text { as TSO contracts } \\
\text { energy intraday to } \\
\text { match changing } \\
\text { wind projections. }\end{array}$ & $\begin{array}{l}\text { No, volume of balancing } \\
\text { services contracted (not } \\
\text { necessarily used) is pre- } \\
\text { specified; also, } \\
\text { generators cannot find } \\
\text { matching partners to } \\
\text { change unit-commitment }\end{array}$ & $\begin{array}{l}\text { Only within portfolio } \\
\text { of utility, difficult to } \\
\text { find matching } \\
\text { partner(s) that } \\
\text { buy/provide energy } \\
\text { matching } \\
\text { demand/technical } \\
\text { constraints }\end{array}$ & No & Possible & $\begin{array}{l}\text { Difficult } \\
\text { because prices } \\
\text { bundle energy } \\
\text { and start-up } \\
\text { cost }\end{array}$ \\
\hline Nordpool & Yes & Access to hydro power & $\begin{array}{l}\text { Not necessary } \\
\text { because of hydro } \\
\text { flexibility, not } \\
\text { possible because } \\
\text { trade only hour-by- } \\
\text { hour and pre- } \\
\text { specified block-bids }\end{array}$ & Yes & $\begin{array}{l}\text { Yes, provides a } \\
\text { program to } \\
\text { integrate DSM. }\end{array}$ & $\begin{array}{l}\text { Difficult } \\
\text { because prices } \\
\text { bundle energy } \\
\text { and start-up } \\
\text { cost }\end{array}$ \\
\hline Spanish system & $\begin{array}{l}\text { Yes, intraday } \\
\text { markets allow re- } \\
\text { dispatch. }\end{array}$ & $\begin{array}{l}\text { There is a day-ahead } \\
\text { secondary reserve } \\
\text { market after the closure } \\
\text { of the day-ahead market } \\
\text { and } 6 \text { additional markets } \\
\text { between the intraday } \\
\text { energy markets. Tertiary } \\
\text { reserve is contracted in a } \\
\text { continuous market. }\end{array}$ & Yes & No & Possible & $\begin{array}{l}\text { Difficult } \\
\text { because prices } \\
\text { bundle energy } \\
\text { and start-up } \\
\text { cost }\end{array}$ \\
\hline PJM type system & $\begin{array}{l}\text { Yes, } \\
\text { ISO can centrally } \\
\text { coordinate } \\
\text { intraday } \\
\text { adjustments }\end{array}$ & $\begin{array}{l}\text { Yes, } \\
\text { All markets are centrally } \\
\text { coordinated. The ISO can } \\
\text { decide if resources bid } \\
\text { into the market are used } \\
\text { to adapt to intraday } \\
\text { changes or are used } \\
\text { close to real-time. }\end{array}$ & $\begin{array}{l}\text { Yes, } \\
\text { Complex bids and a } \\
\text { central optimization } \\
\text { allow for inter } \\
\text { temporal } \\
\text { optimization of each } \\
\text { power plant }\end{array}$ & Yes & $\begin{array}{l}\text { Yes, } \\
\text { PJM implements } \\
\text { several DSM } \\
\text { programmes to } \\
\text { access potential } \\
\text { on the demand } \\
\text { side. }\end{array}$ & $\begin{array}{l}\text { Yes, } \\
\text { bids specify } \\
\text { variable cost, } \\
\text { start-up cost } \\
\text { and technical } \\
\text { constraints }\end{array}$ \\
\hline
\end{tabular}




\section{Developments in the EU towards an integrated market design}

This section explores the developments of the power market designs across the EU and the integration of these power markets in recent years. This raises the question of whether a continuation of the current process can deliver the improvements necessary to accommodate large scale wind and intermittent power station integration in Europe, or whether a more proactive role at the EU level will be necessary to facilitate the shift to an effective power market design.

\subsection{Recent developments in the EU power market}

In 1999 the EU announced its objective of establishing a well-functioning, efficient, and open common market for electricity in Europe. The EU Directive 2003/54 provided a significant step towards achieving this objective by developing an outline for access to networks for the crossborder exchange of electricity. The initial focus was on improving linkage between Member States, primarily addressing the wholesale markets. In 2005 Meeus et al (2005) advised that a second stage of market integration was necessary where cross-border balancing (and intraday) markets should be implemented ${ }^{22}$. The sector inquiry in 2006 indicated that balancing markets were not yet sufficiently well designed, facing high market concentration, high prices, and missing European integration.

In an attempt to mitigate these issues, in 2006, national energy regulators launched a regional initiative to create seven regional markets, as a bottom-up attempt to provide a "practical and achievable way of delivering step-wise progress towards a competitive single European market for electricity." The regional initiative strived to harmonize the market design within each region and to foster the integration of the electricity markets. One measure used to link markets was to apply cross border market coupling, which replaced separate trading for energy and transmission rights between countries, instead using an internal market mechanism to optimize cross border trade.

The Nordic markets were the first to create a coupling of their markets. The Nordpool region implemented market coupling in day-ahead spot and balancing markets. In 2006 France, Belgium, and the Netherlands coupled their day-ahead spot markets. Germany and Denmark joined this day-ahead market-coupling scheme at the end of 2010.

\footnotetext{
${ }^{22}$ NWEMPP et al. (2006) also address the importance of market coupling of intra-day and balancing markets.
} 
The coupling of adjacent energy markets has provided significant improvements over dayahead market results. Transmission lines are used more efficiently and the traded volumes follow the price differences between two regions. Such a market coupling mechanism can be applied to intraday markets and balancing markets as well. Smeers (2008) outlines that the socalled "flow-based market coupling" can provide a reliable platform for such market coupling and is, from a computational perspective, applicable for all markets from day-ahead to realtime, "provided one installs the adequate communication facilities to keep track of energy position and grid status".

Figure 7: Cross border intraday and balancing markets trading arrangements in Europe in the beginning of 2009 (EWI).

\section{Intra-day market}

Continous

$\triangle$ Only for specific time windows

No trading possible

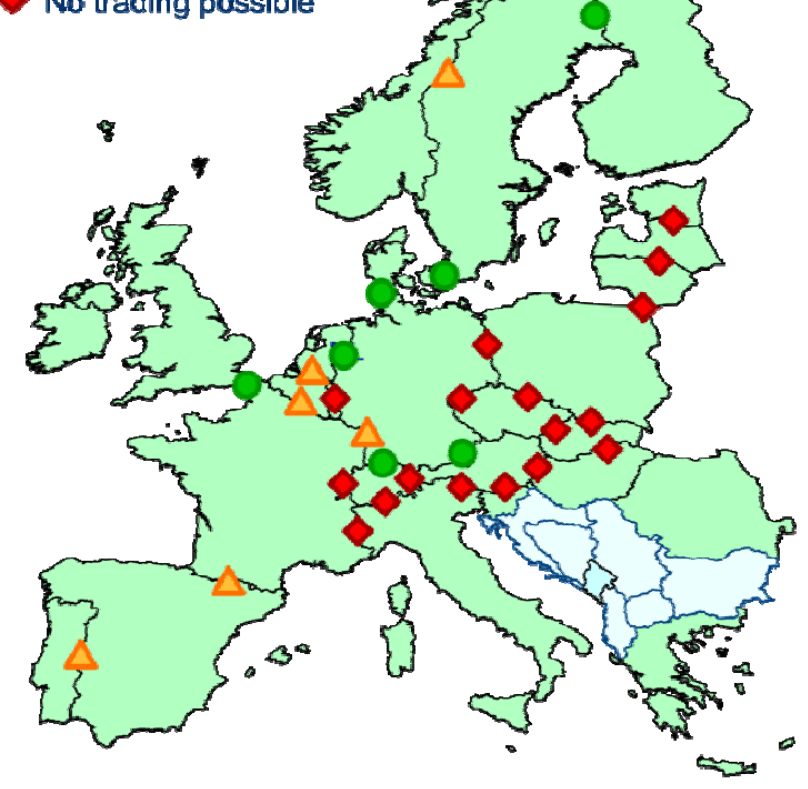

\section{Balancing markets}

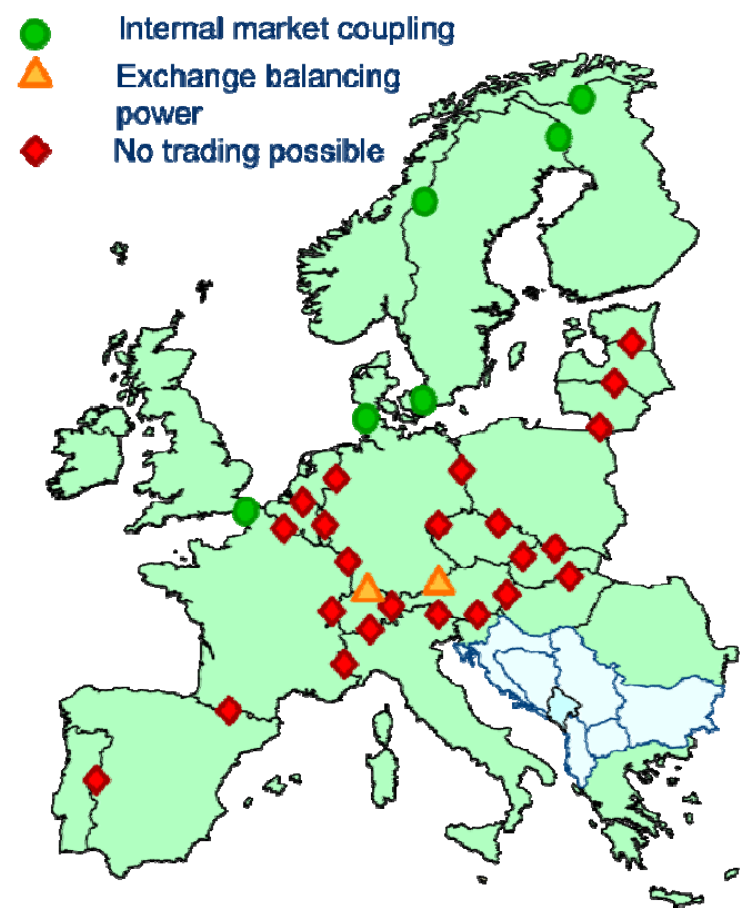

The measures of the regional initiative aim to address spot- as well as balancing- and intradaymarkets. The status reports by ERGEG in 2008 and 2009 revealed that market coupling for balancing markets, however, existed only on a few selected interconnections. So far, market coupling of balancing markets has only been implemented within the Nordic market region and between Germany and the Nordic market region (Denmark). The 2008 report concluded that despite the improvements in the day-ahead market, market design or coupling of balancing markets still had low priority in certain countries. (See Table 3) 
First steps have been taken in recent years towards a common electricity market, however today's intraday and balancing market designs are still far from a fully efficient and harmonised market (Figure 7). The primary constraint to harmonisation of balancing markets is that these markets significantly differ in their market setup (Vandezande et al, 2010). Any approach to harmonising the markets must be able to overcome different gate closure times and to determine a balancing responsible party. The question remains whether the bottom-up approach is sufficient to reach the overall common energy market.

The EU Commission identified the need for a restructuring and harmonisation of the European electricity markets and implemented the third energy package that went into legislation in 2009. In five regulations the European Commission laid out the path for a European electricity regulating body and a harmonisation of the regulating authorities in Europe. The third energy package implements a European TSO (ENTSO-E) and aims to develop a strong and independent European regulatory body (Agency for the Cooperation of Energy Regulators) that complements the national energy regulators and fosters the harmonisation of the common energy market. This energy package departs from the bottom-up approach by implementing strong centralized structures that allow a top-down roll out of a harmonized market system. The EU regulation does not yet provide a clear vision how such a common market for spot, intraday, and balancing markets could be achieved and a binding process is still lacking at the EU-level to ensure harmonisation of rules for all markets (Eurelectric 2009).

Table 1: Congestion Management and Market Coupling: An Overview of the European approaches up to $2010 .^{23}$ Not represented in a regional initiative: Cyprus, Romania, Bulgaria, Malta and Switzerland. Continued on next page.

\begin{tabular}{|c|c|c|c|c|c|}
\hline $\begin{array}{l}\text { ERI- } \\
\text { Region }\end{array}$ & Countries & $\begin{array}{l}\text { Day-ahead } \\
\text { Auction Rules }\end{array}$ & Market Coupling & Intraday & Balancing \\
\hline $\begin{array}{l}\text { Cross- } \\
\text { regional }\end{array}$ & & $\begin{array}{l}\text { Northern, CW } \\
\text { and SW } \\
\text { develop } \\
\text { single set of } \\
\text { auctioning } \\
\text { rules }\end{array}$ & & $\begin{array}{l}\text { No consensus yet; } \\
\text { different market } \\
\text { designs; interference } \\
\text { with balancing } \\
\text { market; flow-based } \\
\text { vs. ATC-based } \\
\text { approach. }\end{array}$ & \\
\hline Northern & $\begin{array}{l}\text { Denmark } \\
\text { Finland } \\
\text { Germany } \\
\text { Norway } \\
\text { Poland } \\
\text { Sweden }\end{array}$ & $\begin{array}{l}+ \\
+ \\
+ \\
+ \\
+ \\
+\end{array}$ & $\begin{array}{l}\text { Market coupling } \\
\text { between Norway, } \\
\text { Finland, Sweden and } \\
\text { Denmark (West) - Since } \\
2009 \text { market coupling } \\
\text { between Germany and } \\
\text { Denmark }\end{array}$ & & $\begin{array}{l}\text { Still some } \\
\text { differences } \\
\text { between Nordic } \\
\text { countries, PL } \\
\text { and DE }\end{array}$ \\
\hline
\end{tabular}

${ }^{23}$ Primary source: ERGEG Status reports. ERGEG (2009) 


\begin{tabular}{|c|c|c|c|c|c|}
\hline $\begin{array}{l}\text { ERI- } \\
\text { Region }\end{array}$ & Countries & $\begin{array}{l}\text { Day-ahead } \\
\text { Auction Rules }\end{array}$ & Market Coupling & Intraday & Balancing \\
\hline $\begin{array}{l}\text { Cross- } \\
\text { regional }\end{array}$ & & $\begin{array}{l}\text { Northern, CW } \\
\text { and SW } \\
\text { develop } \\
\text { single set of } \\
\text { auctioning } \\
\text { rules }\end{array}$ & & $\begin{array}{l}\text { No consensus yet; } \\
\text { different market } \\
\text { designs; interference } \\
\text { with balancing } \\
\text { market; flow-based } \\
\text { vs. ATC-based } \\
\text { approach. }\end{array}$ & \\
\hline Baltic & $\begin{array}{l}\text { Estonia } \\
\text { Latvia } \\
\text { Lithuania }\end{array}$ & & & & $\begin{array}{l}\text { Balancing model } \\
\text { based on Nordic } \\
\text { model to be } \\
\text { developed }\end{array}$ \\
\hline $\begin{array}{l}\text { Central- } \\
\text { West }\end{array}$ & $\begin{array}{l}\text { Belgium } \\
\text { France } \\
\text { Germany } \\
\text { Luxembourg } \\
\text { Netherlands }\end{array}$ & $\begin{array}{l}+ \\
+ \\
+ \\
+ \\
+\end{array}$ & $\begin{array}{l}\text { Full implementation of } \\
\text { market coupling; price- } \\
\text { coupling with SW }\end{array}$ & $\begin{array}{l}\text { Bilateral solutions } \\
\text { between DE-NL, NL- } \\
\text { BE; ongoing public } \\
\text { consultations }\end{array}$ & Low priority \\
\hline $\begin{array}{l}\text { Central- } \\
\text { East }\end{array}$ & $\begin{array}{l}\text { Austria } \\
\text { Czech Rep } \\
\text { Germany } \\
\text { Hungary } \\
\text { Poland } \\
\text { Slovakia } \\
\text { Slovenia }\end{array}$ & & & & Low priority \\
\hline $\begin{array}{l}\text { Central- } \\
\text { South }\end{array}$ & $\begin{array}{l}\text { Austria } \\
\text { France } \\
\text { Germany } \\
\text { Greece } \\
\text { Italy } \\
\text { Slovenia }\end{array}$ & $\begin{array}{l}+ \\
+ \\
+ \\
+ \\
+ \\
+\end{array}$ & $\begin{array}{l}\text { Agreement on market } \\
\text { coupling between Italy } \\
\text { and Slovenia }\end{array}$ & & Low priority \\
\hline $\begin{array}{l}\text { South- } \\
\text { West }\end{array}$ & $\begin{array}{l}\text { France } \\
\text { Portugal } \\
\text { Spain }\end{array}$ & & & $\begin{array}{l}\text { Closed public } \\
\text { consultations }\end{array}$ & $\begin{array}{l}\text { Low priority: } \\
\text { TSO-TSO model } \\
\text { between ES and } \\
\text { PT (MIBEL) }\end{array}$ \\
\hline $\begin{array}{l}\text { France- } \\
\text { UK- } \\
\text { Ireland }\end{array}$ & $\begin{array}{l}\text { France } \\
\text { Ireland } \\
\text { UK }\end{array}$ & & & Explicit auctions & $\begin{array}{l}\text { Full TSO-TSO } \\
\text { model } \\
\text { implemented } \\
\text { between FR and } \\
\text { UK }\end{array}$ \\
\hline
\end{tabular}

\subsection{Way forward}

Apart from the question of what market designs have to be implemented, one of the key issues in 2010 is how to implement an improved power market design. To understand the viability of 
potential processes towards such a power market design, it is necessary to assess the interests of key stakeholders.

For a variety of reasons individual stakeholders might attempt to block, delay, or derail improvements to the power market design:

- Some existing generators might be concerned about an enhanced level of competition that might reduce lucrative margins in the intraday and balancing market.

- Some dominant incumbent generation companies might oppose a change to the market design that removes the benefit of internal balancing within the portfolio and thus removes barriers for the entry of third (competing) generators.

- If traders focus on short-term arbitrage across countries and intraday markets, then improved market design might eliminate all such arbitrage opportunities. Where traders do not have the skills to refocus their activities on longer-term and intra-fuel trading and hedging requirements for the power market (which are facilitated with more robust reference prices), they might oppose the change.

This raises the question of whether the potential opposition by these stakeholders might be compensated by support from stakeholders who benefit from an improved power market design:

- All consumers benefit from reduced system costs (operation, network investment), but constitute a dispersed group that is difficult to activate as they only incur small benefits individually.

- All consumers benefit from increased system security due to improved information exchange and from transparency that facilitates accountability. System operators with good operational procedures might appreciate this clarity, while badly managed TSOs are likely to oppose changes that create more transparency.

- Manufacturers of renewable technologies will benefit from an improved market design that creates flexibility for grid connection of new generation assets and thus avoids delays to the deployment of their products.

- Technology companies will benefit from a clear and transparent market design that offers a clear interface for new technologies for system control and demand side management.

A third group of actors, investors in renewable projects, still seems to be in the process of evaluating their position. 
- Renewable energy producers are concerned that in the process of an improvement to the power market design, they will lose priority grid access. However, an improved market design will provide the benefit of transparent dispatch choice that will prioritise generation technologies with low variable costs such as renewables.

- Renewable energy producers are concerned that market integration implies a shift away from a feed-in tariff with fixed off-take prices to facilitate low-cost financing. In fact, the improved market designs create a clear and transparent trading platform that allows the public counterparty to use feed-in tariffs and sell the output from renewable energy sources. Therefore an improved power market design facilitates the continued use of feed-in tariffs, combining the benefits of efficient system operation and low-cost financing.

There are potential opponents for market improvement within grid owners and generation companies. Given their strong role in domestic policy processes, often as dominant incumbents, it is likely that they will be able to block or derail bottom-up approaches to market design improvement where agreement of all parties is required.

The main winners are European consumers who will benefit from reduced costs, enhanced system security, and an enhanced likelihood of the delivery of renewable objectives. This points to the value of pursuing this initiative from a top-down perspective: e.g. with some form of leadership at the European level. Two options come to mind:

- A European framework specifying a harmonised design. The challenge will be to be sufficiently precise at the level of a European framework to ensure that the various regional implementations will be compatible with each other.

- A European sponsored/supported initiative for one subset of European countries. Nations can join from the beginning, but can also decide to join the initiative at a later stage. This approach is similar to the success of the U.S. American standard market design and the situation of PJM, which is gradually integrating neighbouring TSOs. 


\section{Conclusions}

All long-term electricity scenarios show a large increase in installed wind capacities within Europe in the coming decades. Despite significant improvements in wind forecasting, the dayahead forecasts will induce increasing uncertainty into the European electricity system. It will therefore be essential to make use of two factors: the improving wind forecasts within the hours between the day-ahead market and real-time dispatch, and the full flexibility that the generation, transmission, and demand side of the power system can offer to limit cost increases to deal with this (wind) uncertainty and to ensure full system security.

The power market design therefore has to satisfy six criteria:

- Facilitate system-wide intraday adjustments to respond to improving wind forecasts.

- Allow for the joint provision and adjustment of energy and balancing services.

- Manage the joint provision of power across multiple hours.

- Capture benefits from international integration of the power system.

- Integrate the demand side into intraday and balancing markets.

- Effectively monitor market power.

When comparing market designs based on these six criteria, it becomes apparent that none of the current power market designs applied across European countries fully meets all of them. In contrast, the power market design that has been initially used in PJM and by New York ISO and that has since been adopted in Texas and California does satisfy all six criteria listed in this paper. The assessment in the accompanying paper on congestion management suggests that the PJM type power market design (locational marginal pricing) also performs well with regard to the effective usage of transmission capacity.

Given the positive attributes of an alternative design, this raises the question of whether the current process of gradual EU power market design improvements can facilitate the implementation of such a design. The paper argues that more coordination and initiative at the EU level will be necessary to facilitate the effective operation of the common European markets. While some of the stakeholders might be reluctant to contribute to such a development, European consumers will benefit and EU Member States will be supported in their achievement of the renewable targets formulated in the EU renewable directive. 
The third Energy Package provides opportunities to complement the bottom-up approach pursued so far on European power market design with top-down requirements. One cornerstone of the Energy package is the centralized organizational structure that is currently in place. As many market participants have disincentives to fully support a bottom-up transition to an integrated power market design, the provisions from the Energy Package might become essential in the European pursuit of a harmonized and effective power market design. 


\section{References}

\section{Bartels et al. (2006)}

Bartels M., Gatzen C., Peek M., and Schulz, W.: "Planning of the grid integration of wind energy in Germany onshore and offshore up to the year 2020", International Journal of Global Energy Issues, Vol. 25, no. 3 (2006): 257-275.

\section{Dany and Haubrich (2000)}

Dany, G., and Haubrich, H. J.: "Anforderungen an die Kraftwerksreserve bei hoher Windenergieeinspeisung Requirement for power reserve with high wind energy supply." ET.

Energiewirtschaftliche Tagesfragen 50, Nr. 12 (2000): 890-894.

\section{de la Fuente (2010)}

de la Fuente, Ignacio: "Ancillary services in Spain: Dealing with high penetration of RES" Presentation at CPI Berlin Workshop: The Role of Power Market Design for the Achievement of the 20\% Renewables Target, Brussels, June 10, 2010.

\section{DENA I (2005)}

DENA: "Planning of the Grid Integration of Wind Energy in Germany Onshore and Offshore up to the Year 2020 (dena Grid Study)", German Energy Agency, 2005.

\section{DENA II (2010)}

DENA: "DENA Grid Study II - Study for the integration of a share of 30\% renewable energy in the German electricity market", German Energy Agency, 2010.

\section{ERGEG (2009)}

European Regulators' Group for Electricity and Gas (ERGEG), „ERGEG Regional Initiatives

Progress Report“, available online at http://www.energy-regulators.eu/, November 2009.

\section{EURELECTRIC (2009)}

EURELECTRIC (2009) “ERGEG Regional Initiatives Progress Report - A Eurelectric Response Paper, Available Online at www.energy-regulators.eu, December 2009.

\section{EWI (2010)}

EWI - Fuersch, M., Golling, C., Nicolosi, M., Wissen, R., and Lindenberger, D.: "European RES-E Policy Analysis - Eine modellbasierte Studie über die Entwicklung der Stromerzeugung aus 
Erneuerbaren Energiequellen in Europa und die Auswirkungen auf den konventionellen

Strommarkt", EWI (April 2010).

\section{EWIS (2010)}

EWIS: "European Wind Integration Study - Towards a successful integration of wind power into European Electricity Grids" ENTSO-E Premises (March 2010).

\section{Focken et al. (2002)}

Focken, U., Lange, M., Mönnich, K., Waldl, H.-P., Beyer, H. G., and Luig, A.: "Short-term prediction of the aggregated power output of wind farms - a statistical analysis of the reduction of the prediction error by spatial smoothing effects." Journal of Wind Engineering and Industrial Aerodynamics 90, no. 3 (March 2002): pp. 231-246.

\section{Glachant and Finon (2010)}

Glachant, J.-M., and Finon, D.: "Large-scale wind power in electricity markets", Energy Policy, Volume 38, no. 10, pp. 6384-6386, October 2010.

\section{Hasche (2007)}

Hasche, B.: "Analysen von Prognosen der Windgeschwindigkeit und Windstromeinspeisung." Work package report for the project NetMod, IER University Stuttgart (2007).

\section{Meeus et al. (2005)}

Meeus, L., Purchala, K., and Belmans, R.: "Development of the Internal Electricity Market in Europe", The Electricity Journal 18, no. 6 (July 2005): pp. 25-35.

\section{Muesgens and Neuhoff (2002)}

Muesgens, F., and Neuhoff, K.: "Modelling Dynamic Constraints in Electricity Markets and the Costs of Uncertain Wind Output", EPRG Working Paper Series 0514 (February 2002).

\section{Nabe (2006)}

Nabe, C.: "Effiziente Integration erneuerbarer Energien in den deutschen Elektrizitätsmarkt", Dissertation, TU Berlin, Available Online (March 2006).

\section{Neuhoff et al. (2011)}

Neuhoff, K., Hobbs, B., and Newbery, D., 2011: “Congestion Management in European Power Networks - Criteria to Assess the Available Options", DIW Discussion Paper 1161, 2011. 
NWEMPP et al. (2006)

NWEMPP et al.: "Cross border intraday markets in the North West European electricity market", Position Paper of the North West European Market Parties Platform, available online (June 2006).

Ockenfels et al. (2008)

Ockenfels, A., Grimm, V., and Zoettl, G.: "Electricity market design - The Pricing Mechanism of the Day Ahead Electricity Spot Market Auction on the EEX", EEX Report, European Energy Exchange, Leipzig (March 2008).

\section{Smeers (2008)}

Smeers, Y.: "Study on the general design of electricity market mechanisms close to real time", Study for the Commission for Electricity and Gas Regulation (CREG) (June 2008).

\section{TradeWind (2009)}

TradeWind: "Integrating Wind", project report for the trade-wind study coordinated by the European Wind Energy Association, 2009.

Vandezande et al. (2010)

Vandezande, L., Meeus, L., Belmans, R., Saguan, M., and Glachant, J.-M.: “Well-functioning balancing markets: A prerequisite for wind power integration", Energy Policy, Volume 38, Issue 7, pp. 3146-3154, July 2010.

\section{Von Roon and Wagner (2009)}

Von Roon, S., and Wagner, U.: "The interaction of Conventional Power Production and Renewable Power under the aspect of balancing Forecast Errors", Proceedings of the 10th IAEE European Conference on Energy, Policies and Technologies for Sustainable Economies, Vienna (September 2009).

\section{Weber (2010)}

Weber, C.: "Adequate intraday market design to enable the integration of wind energy into the European power systems", Energy Policy, Volume 38, Issue 7, pp. 3153-3163, July 2010. 